\title{
Origen y límites del crítico en dos publicaciones periódicas literarias. El Renacimiento (México: 1869-1894) y El Nuevo Tiempo Literario (Colombia: 1903-1915, 1927-1929)*
}

Origin and critical limits of two literary journals. $E l$ Renacimiento (México: 1869-1894) and El Nuevo Tiempo Literario (Colombia: 1903-1915, 1927-1929)

Gustavo Adolfo Bedoya Sánchez **

Universidad de Antioquia. Medellín, Colombia

gustavoadolfo00@yahoo.com

\section{RESUMEN}

El objeto del presente estudio es el análisis de dos publicaciones periódicas literarias, de mediados y finales del siglo XIX mexicano la primera, y de inicios del siglo XX colombiano la segunda, en aras de evidenciar la importancia que ambos medios tuvieron

* Este trabajo fue realizado gracias a la Beca para estancias de investigación concedida en el 2011 por el Servicio Alemán de Intercambio Académico (DAAD), bajo la tutoría del PhD Hubert Pöppel, coordinador académico del Forschungszentrum Spanien de la Universidad de Regensburg. La investigación se realizó en el marco del proyecto doctoral "El suplemento El Nuevo Tiempo Literario (Bogotá: 1903-1915, 1927-1929) en los procesos de modernización cultural. La figura del intelectual", que el autor adelanta en el Doctorado en Historia de la Universidad Nacional de Colombia, sede Medellín. La indagación en archivo se logró gracias a los recursos biobibliográficos de la Biblioteca Nacional y la Biblioteca Luis Ángel Arango del Banco de la República, en Colombia; y a los del Instituto Iberoamericano de Berlín (IBI), en Berlín.

${ }^{* *}$ Miembro del Grupo de Investigación Colombia: tradiciones de la palabra (CTP) de la Universidad de Antioquia. Candidato a Doctor en Historia de la Universidad Nacional de Colombia, sede Medellín. Magíster en Literatura Colombiana de la Universidad de Antioquia y Licenciado en Literatura de la Universidad del Valle. Más información acerca del grupo de investigación, en: http://ihlc.udea.edu.co/. 
en el proyecto cultural de modernización de sus naciones, exactamente en el tema de la concreción de la figura del incipiente crítico literario.

Palabras clave: Liberalismo, literatura, periodismo, crítica literaria.

\title{
ABSTRACT
}

The purpose of this study is the analysis of two literary journals, mid and late nineteenth century the first Mexican, and early twentieth century Colombia's second, in order to demonstrate the importance that both media had on the cultural project modernization of their nations, exactly on the issue of the realization of the figure of the nascent literary critic.

Keywords: Liberalism, literature, journalism, literary criticism.

Recibido: 23.12.2011. Aceptado: 27.03.2012.

\section{PERTINENCIA DEL ESTUDIO DE LAS PUBLICACIONES PERIÓDICAS. A MODO DE INTRODUCCIÓN}

\begin{abstract}
nte los altos costos del libro y su limitado radio de acción, las publicaciones periódicas focalizaron, a lo largo de su historia, las prácticas literarias, a saber: la escritura, la lectura y la edición, además de la traducción y el estudio de lo literario. Al mismo tiempo, ante la no profesionalización del escritor, que para el siglo XIX hispanoamericano se denominaba así mismo "publicista", y las altas tasas de analfabetismo, las publicaciones periódicas se dieron a la tarea de formar al hombre de letras. Es de resaltar que en muchas ocasiones una misma persona, o un mismo grupo particular de personas, sustentaba los roles que conllevaban las prácticas literarias, es decir, al tiempo que escribían, publicaban, leían, traducían y criticaban al fenómeno literario. Dado lo anterior, es de resaltar la importancia de estudiar las publicaciones periódicas, ya que en ellas confluyen las prácticas que dan origen al fenómeno literario, y tal como lo establece la sociología de la literatura, las publicaciones periódicas son "instituciones", instrumentos de influencia en los procesos sociales y culturales de las sociedades, pues todo aquello que logran publicar (noticias, opiniones, percepciones y actitudes) es seleccionado de manera consciente (Williams, 1980: 140), así, las publicaciones periódicas no son el receptáculo de lo literario, son las protagonistas, los propios
\end{abstract}


sujetos de la materialización y concreción fáctica de lo literario.

Estudiar la literatura desde una de sus instituciones, las publicaciones periódicas, comporta un cambio metodológico en comparación con la historia literaria tradicional, que en la mayoría de los casos centra su estudio en la obra editada, posteriormente, en formato libro, desconociendo -por ejemplo- lo relacionado con la adaptación y la edición por entregas y apartados, modalidades impuestas por los medios periódicos, y que en la concepción de Chartier (1994 y 1999) y McKenzie (1999) condicionan el sentido del texto y su lectura.

Las presentes páginas tienen como objetivo el estudio de dos publicaciones periódicas, y se sustenta en la idea de que ambos medios, a pesar de sus diferencias, fueron para sus sociedades lugares de enunciación de la crítica, pero sobre todo, lugares de formación del crítico literario.

\section{MÉXICO-COLOMBIA. CONDICIONES SOCIALES DE LA INSTITUCIÓN LITERARIA}

Toda emancipación en Hispanoamérica ha estado acompañada, en el interior de cada nueva nación, de años violentos, batallas y debates políticos, así como de intentos de reconquista o, incluso, de nuevas colonizaciones. México, que en aspectos culturales parece llevar la delantera, no fue la excepción, y luego de una década buscando la independencia sufrió el desgaste de guerras civiles e intentos de invasión por parte de los Estados Unidos y Francia. 1821 no fue la fecha de su soberanía definitiva, aún debió reafirmarse ella misma y por ello conservadores y liberales se debatieron el control del país; incluso, a mediados del siglo XIX México continuó desgastándose en querellas domésticas: Revolución de Ayluta (1854), Guerra de los Tres Años (1858-1860), invasión francesa estimulada por los conservadores (1862), etc. De esta manera, tan solo a finales de los años sesenta del siglo XIX, México encontró un momento de tranquilidad política (si tal cosa existe), y las condiciones sociales necesarias para llevar a cabo la organización de una institución cultural, lo suficientemente fuerte para abanderar el proyecto de "progreso" nacional desde las artes, en especial desde la literatura. Este proyecto lo lideraron hombres como Ignacio Ramírez "El Nigromante" (18181879), acalorado político y periodista liberal, pero también, "animadores" culturales como Ignacio Manuel Altamirano (1834-1893), uno de los más importantes promotores de la literatura mexicana, y el más destacado discí- 
pulo del primero ${ }^{1}$.

Abanderado de las políticas liberales republicanas, Altamirano lideró un movimiento intelectual que lo diferenció de sus contemporáneos, incluso de su maestro: impuso la acción de la pluma sobre la discusión política y el filo de la espada. Cada una de sus actividades como hombre público, como ciudadano, estuvo encaminada a la creación de espacios intelectuales, a la conformación efectiva de una institución cultural mexicana. Por ejemplo, organizó tertulias literarias, conformó cenáculos y asociaciones de intelectuales en torno a diversas disciplinas del saber, fundó varios medios de publicación periódica en los que quedaron plasmadas las muestras de ingenio de su generación y la siguiente (la que él mismo intentó crear), y a través de su obra literaria marcó el camino a seguir, el cual se puede resumir en lo siguiente: México necesita una literatura mexicana, que sea "bella" y "propia" (reconociendo lo universal sin imitarlo), pero sobre todo "moral" en cuanto no ofende a Dios ni a las buenas costumbres, por último, una obra "útil” en la constitución de los individuos y de la nación.

El caso colombiano no dista mucho del mexicano. Los años posteriores a la Declaración de Independencia arrastran en la historiografía tradicional con el paradójico mote de "Patria Boba" (1810-1816), declarada así ante los escarceos de los dos partidos políticos por la manera en que debía organizarse el gobierno: desde el centralismo (conservadores) o el federalismo (liberales). Las luchas internas entre compatriotas facilitó la reconquista española, la cual se logró sortear de la mano de Simón Bolívar para entrar (y no volver a salir) en una serie bochornosa de luchas civiles, de cambios en la Constitución, de cambios en el nombre del país, de reelecciones presidenciales, de amputaciones del espacio geográfico, de afectos con la iglesia católica y, sobre todo, de censura ideológica programática.

${ }^{1}$ Si gran parte del desarrollo de la cultura de una nación se encuentra ligado a las decisiones del poder político, la vida de los hombres de letras es indisoluble a las contiendas y disputas ideológicas. Así, Altamirano, indígena de una olvidada población, logró siendo muy joven ingresar al Instituto Literario de Toluca, el más prestigioso de la época, pero a sus 18 años, en 1852, debió retirarse por dar a conocer sus ideas políticas en un periódico de la ciudad. En 1854 suspendió sus estudios de Derecho en el Colegio de San Juan de Letrán, de la ciudad de México, para tomar las armas en la Revolución de Ayluta, revolución que tenía como meta derrocar al Presidente Antonio López de Sannta Ana. En 1858, durante la Guerra de los Tres Años (1858-1860) apoyó difundiendo panfletos y acompañando a los liberales en la Cámara de Diputados, hasta que retomó las armas ante los asesinatos de algunos de sus compañeros. Durante la invasión francesa, en 1862, en contra de Maximiliano II (impuesto como Emperador de México por Napoleón III, sobrino de Napoleón Bonaparte), Altamirano luchó como coronel auxiliar de la Guardia Nacional hasta conseguir la victoria de los liberales junto con Benito Juárez. Sobre la vida militar de Altamirano, véase: Sánchez (1964). Sobre la historia política mexicana véase al propio Altamirano en Historia y política de México 1821-1882 (1958). 
Así, para 1884 el partido conservador logró sofocar los impulsos liberales por retomar el poder, el Presidente en ese entonces no era otro que el poeta Rafael Núñez, secundado por su homólogo Miguel Antonio Caro, miembros del partido político que liderará el desarrollo del país hasta el adelantado año de 1930, bajo el proyecto denominado como la "Regeneración", en lo que se ha conocido el periodo de la Hegemonía Conservadora. Bajo esta realidad social se fundarán cientos de proyectos culturales que deberán callar ante la censura, o que deberán suspenderse ante las batallas o ante la falta de recursos para continuarlos. Uno de esos proyectos que sobresale por el tiempo que duró ofreciendo un espacio a la ejecución del arte literario fue el dirigido por el liberal Carlos Arturo Torres (1867-1911), el suplemento El Nuevo Tiempo Literario².

A diferencia de Altamirano, quien ejerció su labor intelectual como protector de la literatura bajo los parámetros del mismo gobierno que él ayudó a formar, Torres intentó liderar sus proyectos bajo la mira de un gobierno que lo consideró sospechoso y persona no grata, incluso, lo que parece peor, en muchas situaciones de su vida fue considerado como tal por sus propios compañeros de partido. Sin embargo, la publicación de los medios literarios del mexicano se llevó a cabo en tiempos de mayor dificultad técnica, asimismo, los índices de analfabetismo eran más altos y la necesidad cultural de la lectura escasa; en contraposición, el colombiano desarrolló su suplemento bajo la protección técnica y financiera del diario más importante de la época El Nuevo Tiempo, y en momentos en que la lectura y la compra de papeles periódicos era, más o menos, una realidad efectiva entre los miembros de la sociedad capitalina.

${ }^{2}$ Uno de los más interesantes perfiles biográficos de la juventud de Torres fue escrito por Ismael Enrique Arciniegas, justamente para el suplemento El Nuevo Tiempo Literario (No 979-1, del 1 de junio de 1905: 5-10). Arciniegas relata que durante sus vacaciones se reunía con Torres en torno a la poesía a pesar de sus diferencias políticas. Ambos colaboraron en el folletín La Luz de Rafael M. Merchán y por algún tiempo vivieron en una habitación ubicada en el segundo piso de la Imprenta de José Rivas Groot, quien los reunió, junto con José Asunción Silva, Julio Flórez, Diego Uribe y otros, para empezar una serie de tertulias que desembocaron en la publicación de Victor Hugo en América, en la que autores hispanoamericanos tradujeron al francés. Luego tuvieron la idea de publicar una revista literaria pero finalmente se decidieron por el libro: La lira nueva (que en principio se iba a denominar Arpas amigas). Finalmente, Arciniegas cuenta que Torres dejó a un lado su carrera poética para dedicarse de lleno al periodismo: "Sus cantos vibraban, llenos de ternura y armonía, pero entre las tormentas que levantaba su pluma no había oídos sino para su prosa centellante, y no había aplausos sino para sus acentos viriles de polemista y de luchador" (Arciniegas: El Nuevo Tiempo Literario, No 979-1, del 1 de junio de 1905, p. 9). 


\section{PROSPECTOS, INTRODUCCIONES Y OTRAS CARTAS DE NAVEGACIÓN}

El prospecto de El Renacimiento, escrito por Altamirano en 1869, plantea que en tiempos de guerra el arte no prospera: es necesaria la tranquilidad social para llevar a cabo la reflexión que necesita el estudio histórico o la creación literaria. Por suerte, dice el autor, la actualidad mexicana descansa de las querellas y de esta manera se presencia un "renacer" de las artes. El mexicano se detiene en la descripción de cada una de las nuevas producciones escritas por los jóvenes autores, y finalmente establece la meta de su publicación: "Con el objeto, pues, de que haya en la capital de la República un órgano de estos trabajos, un foco de entusiasmo y de animación para la juventud estudiosa de México, hemos fundado este periódico" ( $E l$ Renacimiento: 1869: 5). Por su parte, la introducción de El Nuevo Tiempo Literario escrita por Torres plantea que el suplemento nació en 1903: "época de singular ardentía política y aciaga y doloroso cual ninguna de las que ha atravesado la República" (El Nuevo Tiempo Literario: 1904, № 297-1: IV), se refiere al final de la Guerra de los Mil Días (1899-1902), la posterior firma de tratados, la tensión política y la separación de Panamá (1903), etc. El objetivo de la publicación colombiana: "obsequiar á los abonados á un periódico de propaganda y de combate, con páginas serenas, no contaminadas con la acerbía (sic) de la pasión" (El Nuevo Tiempo Literario: 1904, N 297-1: III). Así, El Renacimiento espera recoger los frutos de los tiempos de la paz, mientras El Nuevo Tiempo Literario alejar a los lectores de las batallas, ofrecerles un oasis en medio de las angustias.

Ambos autores detallan el tipo de colaboraciones que harán parte de sus publicaciones: en El Renacimiento tendrán cabida "artículos históricos, biográficos, descripciones de nuestro país, estudios críticos y morales" ( $E l$ Renacimiento: 1869: 5), mientras en El Nuevo Tiempo Literario "artículos de crítica literaria, novelas cortas, cuentos ligeros, poesías, viajes, variedades, etc." (El Nuevo Tiempo Literario: 1904, No 297-1: III). De manera evidente la publicación mexicana no subraya la presencia de lo literario con tanto ahínco, mientras la publicación colombiana tan sólo hace mención a una forma metaliteraria, pero es claro que las dos obras están compuestas tanto de textos ficcionales como de textos que estudian y analizan al fenómeno literario, es decir, de textos críticos.

En este punto es necesario entender que dichas formas metaliterarias que hacen alusión al "análisis" y al "estudio" de lo literario no deben ser pensadas en términos actuales, sino que eran formas escriturales que agrupaban 
también la noticia, el comentario, la impresión y el rumor malintencionado. Asimismo, es necesario entender que "lo literario" abarcaba tanto lo relacionado con la obra misma (recursos estilísticos, formales, temáticos) como lo externo a ella (empezando por la propia vida civil y política del escritor, así como los reconocimientos que le eran otorgados, los celos, envidias y competencias, etc., hasta las escuelas, movimientos, tradiciones y corrientes que re-significaban a la obra).

Para Altamirano las participaciones debían mezclar lo "útil” con lo "dulce" (El Renacimiento: 1869: 5), y para Torres la "belleza" con la "verdad", además de que cada participación debía valerse del propio "mérito de lo escrito y el de su moralidad” (El Nuevo Tiempo Literario: 1904, No 297-1: III). Resulta indiciario el hecho de que la publicación de principios del siglo XX apele a la moralidad y no lo haga la publicación de mediados del siglo XIX. Asimismo, se resalta el hecho de que el suplemento apele también al "mérito" del escrito: ¿acaso a sus facultades propiamente literarias? Mientras tanto, Altamirano sintetiza las propiedades de la literatura (que está a punto de fundar), en una fórmula de Horacio, la cual resulta acorde con su proyecto didáctico de constitución de una literatura nacional que debía también, ante los inexpertos lectores, resultar agradable ${ }^{3}$.

Altamirano cierra su prospecto con un párrafo en el que moldea a todos los literatos junto con los hombres políticos en un mismo principio: la nación: "Llamamos á nuestras filas á los amantes de las bellas letras de todas las comuniones politicas, y aceptaremos su auxilio con agradecimiento y con cariño. Muy felices seríamos si lográsemos por este medio apagar completamente los rencores que dividen todavía por desgracia á los hijos de la madre común" (El Renacimiento: 1869: 6. El subrayado es nuestro). Torres hace lo propio, aunque no tan categóricamente: en el suplemento tendrán acogida "autores de diversas y aun opuestas escuelas, épocas, nacionalidades y opiniones" (El Nuevo Tiempo Literario: 1904, No 297-1: III), "Con el fin supremo de servir á Colombia, al arte, á la justicia y á la verdadera libertad" (El Nuevo Tiempo Literario: 1904, No 297-1: IV).

Si las palabras de Altamirano resuenan desde el convencimiento que significó adelantar un proyecto de su partido, pero sobre todo un proyecto de su inteligencia, las palabras de Torres irrumpen temerosas de toda aseveración, es más, dicha introducción se escribió luego de la compilación del primer tomo de la publicación como prospecto, pero sobre todo como "ba-

${ }^{3}$ En El arte poética de Horacio, también conocida como Epistola a los pisones, se pone de presente en los versos 766-768, la famosa fórmula Miscuit utile dulci: "Mas todos con su voto contribuye/Al que enseñar y deleitar procura,/Y une la utilidad con la dulzura” (1776: 52 y 54). 
lance" del primer año de funciones. La incomodidad de las palabras resulta sintomática de las pesadumbres políticas de la sociedad, lo cual se evidencia mucho más fácil en los editoriales del periódico que contenía al suplemento ${ }^{4}$.

Considerado como "el primer gran periódico del siglo [XX]" (Vallejo, 2006: 390), El Nuevo Tiempo (1902-1932) fue dirigido por Nicolás Pontón y los experimentados José Camacho Carrizosa y Carlos Arturo Torres, quienes ya habían logrado cierto éxito en La Opinión Pública (1897-1899) y La Crónica $(1897)^{5}$. El Nuevo Tiempo editó seis páginas en gran formato atiborradas de anuncios publicitarios, acompañados de las secciones de cables internacionales, así como la reseña de la lectura de los diarios regionales y de la capital. El periódico empezó apareciendo tres veces por semana, luego de manera diaria, y un año después sumó a la edición dominical, de manera gratuita, el suplemento. Es evidente que el mayor número de textos del diario eran noticias de la actualidad política colombiana e internacional, por ejemplo, el caso de la separación de Panamá y las luchas intestinas entre los partidos políticos. Lo anterior se evidencia en los editoriales de Torres, quien se opone a la guerra -incluso en contravía de la decisión de su partido-, ante lo cual manifiesta: "La alta función del liberalismo es convencer, no matar, fundar escuelas no fomentar cuarteles" ( $\mathrm{N}^{\circ} 161$ del 25 de noviembre de 1902), y: "Con la guerra civil no se conquista la libertad civil, en la escuela de la violencia no se aprende la tolerancia; en los cuarteles no se adquiere la capacidad cívica; en las matanzas no se aprende a respetar la vida humana" ( $\mathrm{N}^{\circ} 22$ del 12 de junio de 1902. El subrayado es nuestro). Tal capacidad de tolerancia marcará el rumbo de sus proyectos, y por ello, la confluencia de textos de diversos autores, pertenecientes a distintos credos políticos, será tan patente en su suplemento ${ }^{6}$.

${ }^{4} \mathrm{Al}$ tratarse de un suplemento dominical El Nuevo Tiempo Literario no estaba acompañado de Notas editoriales, Prólogos o Introducciones, como sí sucedía en El Renacimiento, subtitulado por su propio editor como Periódico literario. El suplemento colombiano contenía en su interior las participaciones ficcionales y críticas a manera de una antología o florilegio, en comparación con las páginas de El Renacimiento en donde las creaciones y las críticas resultaban condicionadas por las Introducciones o Crónicas que abrían cada ejemplar. Así, la dirección ideológica del suplemento parece descansar en las propias publicaciones de Torres, tanto en el interior del suplemento como del diario: en el primero se trató, en la mayoría de las ocasiones, de estudios y análisis de la literatura extranjera, mientras que en el segundo sus participaciones se centraban en las discusiones políticas de la actualidad. No sobra indicar también que visto al día de hoy, la publicación de Altamirano tiene más características de una revista que de un periódico, al concentrarse sistémicamente en un objeto como lo fue el estudio de la literatura mexicana.

${ }^{5}$ Posterior a su labor en El Nuevo Tiempo y su suplemento, Torres inició el proyecto La Civilización (1910).

${ }^{6}$ Torres dejó su labor en el diario y el suplemento cuando fue llamado por el gobierno 


\section{PRESENCIA DE LO LITERARIO}

En El Renacimiento los textos en prosa ocupan un lugar primordial: novelas, cuentos, biografías, traducciones, obras dramáticas, pero sobre todo las "Revistas de teatro" a cargo de Manuel Peredo; los "Estudios de literatura" de Ignacio Ramírez; y los "Boletines bibliográficos", revisiones, estudios y las "Crónicas de la semana" a cargo de Ignacio Manuel Altamirano 7 . Los textos críticos son los que ocupan un mayor porcentaje de las páginas de El Renacimiento, asimismo, la totalidad de dichas páginas están escritas por mexicanos, y aunque en ocasiones den cuenta de tradiciones literarias extranjeras, todo está encaminado a revisar, evaluar y exponer el pasado literario mexicano, pero principalmente, las oportunidades materiales e intelectuales de su presente. Lo anterior cumpliendo con el objetivo preliminar de dar el espacio a la escritura de la juventud (aunque gran parte de los textos son de Altamirano, Peredo y Ramírez, justamente los menos jóvenes de los colaboradores). En El Nuevo Tiempo Literario la poesía ocupará el lugar central, tal como lo hizo en la mayor parte de las publicaciones periódicas colombianas del siglo XIX y principios del XX. Sin embargo, ya que el suplemento logró sobrevivir durante un poco más de 14 años, el número de textos en prosa, pero sobre todo el número de textos críticos es considerable. De sus más de 6.000 participaciones (de las cuales la mitad son textos poéticos), más o menos un $14 \%$ de las publicaciones son textos críticos, un promedio de 903 publicaciones $^{8}$. Estos textos son, en su mayoría, traducciones de artículos o capítulos de libros extranjeros, así como algunos estudios y reseñas de autores hispanoamericanos. A diferencia de El Renacimiento, el suplemento está consagrado a la publicación de autores reconocidos como canónicos, tanto a nivel nacional (Jorge Isaacs, por ejemplo) como a nivel internacional (Goethe, Víctor Hugo, Tolstoi, Leopardi, Shakespeare, Cervantes, entre

conservador como ministro del Tesoro. Habían pasado muchos lustros desde la última vez que un gobierno llamaba a sus filas a un certero rival; sin embargo, su oposición crítica frente a los lineamientos conservadores, pero también su oposición a algunos lineamientos de su propio partido ya lo habían hecho escribir, en carta a su amigo Fidel Cano: "Yo he sido uno de los escritores más atacados por la Regeneración, y nunca esos golpes me dolieron como éstos que recibo de mis hermanos" (2001: 663). Se refiere a los ataques de sus compañeros de partido ante sus labores como secretario del Comisionado en Europa, ante el negocio del Canal de Panamá, en 1889.

${ }^{7}$ En el caso de los textos poéticos, eran regulares las participaciones de Manuel M. Flórez, José M. Bandera, Luis G. Ortiz, Luis Ponce, José Sebastián Segura, Isabel Prieto de Landázuri, y las traducciones e imitaciones de textos de Petrarca, Novalis, Musset, Campoamor, Lamartine, pero sobre todo de Víctor Hugo.

${ }^{8}$ Véase más información del suplemento y la historia de las publicaciones periódicas literarias colombianas, en: Bedoya, 2010a, 2010b y 2011. 
muchos otros). Se publicaron novelas, cuentos, obras de teatro, crónicas, poesías, los ya citados textos críticos: reseñas, estudios, biografías, notas, etc. Y aunque en su introducción Torres indique que los noveles autores también tendrían espacio en las páginas del suplemento, la verdad es que la mayor parte de las contribuciones la hacen los jóvenes pero no noveles autores que conforman la intelectualidad colombiana de finales del siglo XIX y principios del XX: Baldomero Sanín Cano, Ismael Enrique Arciniegas, el propio Torres, Max Grillo y Antonio Gómez Restrepo, siendo los más jóvenes (para los años finales del suplemento en la década de 1920), y quizás menos conocidos, José Eustasio Rivera y Eduardo Castillo, aunque los dos ya habían logrado algunas publicaciones en la prensa y con ello cierto renombre. Otra gran diferencia entre los dos órganos es que el colombiano explora en menor medida el tema de su propia literatura nacional, y mucho menos el de dicha literatura en su actualidad. De esta manera, el suplemento patentaba sin ninguna dificultad su dirección de alta tolerancia y convivencia en el aspecto literario, publicando lo clásico, que no se prestaba tan fácilmente a controversias, así como cumplía con el objetivo de la publicación: abonar a sus lectores con muestras literarias "meritorias".

Aunque Altamirano sea reconocido en Hispanoamérica -generalmente- como un novelista menor, en su país las diversas investigaciones en torno a su nombre han hecho relucir su faceta de político, militar e historiador. Asimismo, es evidente que paralelo a dichas labores Altamirano encontró en la crítica del ambiente cultural un instrumento para coordinar su magisterio intelectual. Cultivó una serie de subgéneros periodísticos y críticos literarios, mitad estudio sistémico, mitad comentario impresionista (justamente mezclando lo "útil" con lo "dulce"), tales como el estudio, el artículo, la reseña, la bibliografía y la revista o revisión, en los que está descrita la historia, paso por paso, de la realidad cultural y literaria del México de mediados y finales del siglo XIX, deteniéndose en su presente, en donde establece además la relevancia de la literatura contemporánea y el papel patriótico que ella debe cumplir en las nuevas generaciones ${ }^{10}$. Estos géneros y el estilo didáctico de Altamirano informan e instruyen a una

\footnotetext{
${ }^{9}$ Por ejemplo, la constante publicación de textos de y sobre Víctor Hugo, autor recepcionado tanto por los liberales como por los conservadores. Recuérdese la publicación que reunió a Rivas Groot y a Arciniegas junto con Silva y Torres: Victor Hugo en América (Nota a pie de página número 4).

${ }^{10}$ Acerca de los estudios realizados por el autor sobre la tradición literaria mexicana, pero en especial sobre su presente, así como detalles acerca de la configuración de las veladas literarias y los cenáculos, y sus ideas en torno a la prensa como plataformas culturales para los noveles autores, en: Altamirano, 1988a, 1988b y 1989.
} 
sociedad que empieza a aprender la manera en que las políticas liberales tienden por el "progreso" social. De allí, por ejemplo, la atención prestada a la descripción de las veladas literarias (conformadas por el propio Altamirano, y consideradas el germen cultural de El Renacimiento); o los constantes listados bibliográficos a lo largo de la publicación, en los que se invita a los lectores a comprar los títulos, ya que, además de estar bien escritos, son ejemplos de inteligencia y amor por lo propio. $\mathrm{O}$ sus descripciones y críticas de la literatura contemporánea, aún no publicada pero leída en público, donde Altamirano, "el maestro" (así se le llamaba en las veladas), aconseja e invita a la corrección. También son de resaltar las revisiones sobre la enseñanza primaria en México; o sus fuertes críticas en contra de la moda de la zarzuela y el can can; o los positivos comentarios acerca de la llegada de compañías de teatro y el fomento de esta afición en México. Por ejemplo, Altamirano invita a sus lectores a no perderse los espectáculos teatrales, aunque sabe que son costosos y por ello sostiene en las páginas del periódico una larga justificación de lo que ha sido el teatro en la historia universal, todo con el ánimo de seducir al lector para que invierta su dinero $\mathrm{y}$ asista a las funciones ${ }^{11}$.

Cada una de las páginas de su publicación tienen la finalidad programática de educar y corregir a los jóvenes en pro de sus propias obras, lo cual logrará el "renacimiento" (de allí el título de la publicación) de la literatura mexicana, y por ende (así lo cree Altamirano) el progreso de la sociedad nacional. Incluso, la reseña biográfica de un autor como Dickens le permite a Altamirano dar una lección a los jóvenes escritores y ciudadanos: luego de resaltar las cualidades del inglés, se detiene sobre su alta "moralidad" que le permite describir su propio país, lo cual resulta entonces ejemplar (no sobra indicar que la reseña está acompañada de la relación de las obras completas del inglés y comentarios descriptivos sobre la mayoría de ellas): "Sinceramente deseamos que el género de Cárlos (sic) Dickens se cultive en México. Sus ventajosos resultados serian palpables en poco tiempo, y el gusto por la lectura cundiría entre el pueblo prodigiosamente" (enero 26 de 1869: 67).

Por su parte, Torres es reconocido en Colombia como un intelectual que no ha tenido la suerte de ser rescatado del olvido. La edición de sus Obras

${ }^{11}$ Por ejemplo, el estudio: "El género bufo en Grecia, en Roma, en Italia, en España, en Inglaterra, en Francia", aparecido el 17 de julio de 1869. Evidenciar los problemas materiales de la cultura (lo costosa que puede llegar a ser) hace que Altamirano critique en diversas ocasiones a su propio gobierno, ya que con bastante frecuencia -según sus propias palabras- abandona esta fracción de la patria y se encarga tan solo de lo político y militar. 
(2001, 2002a y 2002b) demuestra el esfuerzo de su, quizá, único crítico sistemático: Rubén Sierra Mejía, quien desde el inicio de su proyecto planteó que aún no se ha hecho la recopilación total de sus obras, y mucho menos el estudio certero de las mismas (en Torres, 2011: XVII). La obra ensayística de Torres publicada en formato libro es la más conocida en la actualidad, sin embargo, en un principio el autor se destacó en los diarios y las publicaciones periódicas a través de algunas muestras poéticas, pero sobre todo a partir de sus traducciones y estudios de la literatura extranjera. Dichos estudios tienen la cualidad de resultar mucho más objetivos que los de Altamirano (como era de esperarse gracias al paso del tiempo). Son trabajos casi conceptuales, y en una primera lectura se podrían apreciar como imparciales. Sin embargo, detrás de la supuesta imparcialidad y su finalidad "expositiva", se esconden las fuentes de una crítica a la cultura colombiana producida por la Regeneración, sobre todo en lo que tiene que ver con la censura de las ideas. Tal como ya lo había establecido en el aspecto político, en los editoriales del diario, Torres invita a los lectores del suplemento al respeto por la diversidad de las maneras de pensar. No es gratuito que una de sus primeras colaboraciones en el suplemento esté dedicada a la figura de un intelectual contemporáneo (no literato): Waldeck-Rousseau ${ }^{12}$; o que establezca como paradigma la vida y obra de autores, pues, como en el caso de Altamirano, cada una de las páginas escritas por Torres deriva en lección. Así logra, por ejemplo, una sincronía en la crítica que hace del poeta colombiano Julio Flórez (1867-1923), figura contemporánea a Torres pero totalmente opuesta, ideológicamente hablando. Lo anterior no es motivo para que Torres lo descalifique, como podría haber resultado bajo los lineamientos de la Regeneración, al contrario, Torres alude al crítico y no al hombre para señalar y remarcar las diferencias, al tiempo que rescata y aplaude sus logros, así, el crítico establece que Flórez es un "soñador", un "poeta subjetivo" limitado a su alma, que poco le interesa el mundo público y político: "No ha viajado, no ha ocupado ningún puesto público; su luminoso talento no ha sido lla-

${ }^{12}$ Diplomático francés destacado en el famoso caso Dreyfus. Su "equilibrada" modalidad intelectual, dice Torres, expuso mejor que nadie que la adhesión política no implica la abdicación de las propias convicciones, lo cual debe ser guía para todo hombre ( $\mathrm{N}^{\circ} 812-24$ del 20 de noviembre de 1904: 369-374). Recuérdese que la acusación de espionaje sobre el capitán de origen judío Alfred Dreyfus conmocionó a los franceses y al mundo entero durante los años que van de 1894 a 1906, es el mismo caso que provocó el Yo acuso de Émile Zola y de tantos otros hombres que lograron demostrar que detrás de la acusación se escondían cuestiones de un violento nacionalismo y antisemitismo. Justamente es la escena política que da origen al nombramiento de "intelectual" en hombres como Zola. No sobra decir que el diario El Nuevo Tiempo siguió cada paso de los avatares del juicio y que El Nuevo Tiempo Literario le dedicó varias columnas a la obra de Zola. 
mado á cooperar en ninguna forma en los destinos de su patria" (593), pero lo anterior no es motivo para desconocerle el que sea uno de los poetas más originales de su época, cultivador de las más "vigorosas formas de la genuina poesía castellana" $(594)^{13}$.

También vale resaltar uno de los trabajos más importantes de Torres escrito en principio para la prensa y que luego alcanzó la edición en formato libro. Se trata del ensayo "Del movimiento literario en la Europa contemporánea" ${ }^{14}$, en el que el autor logra hacer confluir las distintas maneras de pensamiento de la intelectualidad occidental contemporánea: ingleses, alemanes, italianos, portugueses, franceses e incluso rusos. Se trata de una "parcial revista, rápida y forzosamente incompleta" (El Nuevo Tiempo Literario: 1907, $\mathrm{N}^{\circ} 1.674-22$ del 23 de junio: 348), sobre las ideas que se imponen siempre buscando en principio el destierro de las anteriores: "los revaluadores (sic) se ven revaluados á su turno, y en la perpetua transvaluación ${ }^{15}$ de todos los valores, los ídolos envejecen con rapidez siempre creciente -para rejuvenecer talvez (sic) mañana" (El Nuevo Tiempo Literario: 1907, $\mathrm{N}^{\circ}$ 1.674-22 del 23 de junio: 347). Así, luego de realizar su estudio por las ideas de los autores más importantes de cada nación, el crítico, imparcial y tolerante, concluye y advierte:

No hay, pues, en realidad un espíritu viejo y otro nuevo que, como conceptos absolutos, partan el sol, y en cuyas banderas esté escrito: aquí tradición y allá porvenir. La mente humana es á la vez múltiple en sus formas, una en su esencia, modificada y modelada en cada caso por las circunstancias ambientales; verdad que nos llevará á no rechazar á los recién venidos, y lo que es todavía más generoso y más racional, á no desconocer á los que han pasado (El Nuevo Tiempo Literario: 1907, № 1.722-29 del 11 de agosto: 465).

${ }^{13}$ Nota escrita en 1896 pero publicada en 1905. Véase en el suplemento: $\mathrm{N}^{\circ} 931-38$ del 9 de abril de 1905: 593-595.

${ }^{14}$ El ensayo fue recogido en Estudios varios, pero su primera edición es la del suplemento, véase en: $\mathrm{N}^{\circ}$ 1.674-22 del 23 de junio de 1907: 347-350; continúa: 1.680-23 del 30 de junio de 1907: 368-369; continúa: $\mathrm{N}^{\circ} 1.687-24$ del 7 de julio de 1907: 379-382; continúa: $\mathrm{N}^{\circ} 1.694-25$ del 14 de julio de 1907: 395-397; continúa: № 1.701-26 del 21 de julio de 1907: 411-412; continúa: 1.70827 del 28 de julio de 1907: 433-434; continúa: $\mathrm{N}^{\circ} 1.715-28$ del 4 de agosto de 1907 y concluye: $\mathrm{N}^{\circ}$ 1.722-29 del 11 de agosto de 1907: 464-466. Este ensayo toma constantemente apartados de otro ensayo del autor: "De las modernas escuelas literarias", escrito en 1901 pero publicado en el primer número del suplemento, es más, es el primer texto del cuadernillo ( $\mathrm{N}^{\circ}$ 207-1, del 24 de mayo de 1903: 1-3), pero que aún hoy en día no ha alcanzado la edición en otros formatos.

${ }^{15}$ Realmente alude a la "transvaloración de todos los valores", expresión clásica de una de sus lecturas favoritas: Nietzsche. 


\section{APARICIÓN Y NUEVOS TIEMPOS DEL CRÍTICO. A MODO DE CIERRE}

Altamirano necesitó de la crítica para redundar en la acción de su proyecto cultural: realmente está educando a los individuos que prepara como escritores y lectores de la próxima generación. Su meta y límite es el nacionalismo liberal. En su estudio sobre la novela se alcanza a percibir más claramente su propuesta, para Altamirano en 1868 la novela no es un cuento imaginativo sin límite alguno (como regularmente era calificada, género por antonomasia "diabólico"), al contrario, para el mexicano es un "género superior", del cual es necesario apartar la fantasía y hallar: "En el fondo de ella el hecho histórico, el estudio moral, la doctrina política, el estudio social, la predicación de un partido o de una secta religiosa: en fin, una intención profundamente filosófica y trascendental en las sociedades modernas. La novela hoy suele ocultar la biblia de un nuevo apóstol o el programa de un audaz revolucionario" (1988a: 39).

El proyecto de Altamirano está por encima de credos, al nivel de los hombres, de los ciudadanos organizadores de la sociedad. Su propuesta quedará plasmada en la entrega por capítulos de su novela Clemencia (1869), durante la segunda época de El Renacimiento, y una vez se finalice el proyecto editorial de su periódico anunciará que su obra ha alcanzado la edición en formato libro. Es necesario tener en cuenta que esta obra literaria ha perdurado en la historia literaria hispanoamericana, más que como un ejemplo enteramente literario, como un testimonio de las consideraciones políticas de la época en la cual fue escrita, sobre todo, de la propuesta ideológica de cierto conjunto de liberales cultos, letrados, cuya figura Altamirano representa mejor que ninguno: el indígena semisalvaje que logró, gracias a la educación, convertirse en el prohombre político y el afamado escritor, reconocido, consultado y visitado, incluso, por los escritores conservadores, pues no es gratuito que no hubiera ningún escritor a mediados y finales del siglo XIX que no fuera organizado, clasificado y evaluado por el propio Altamirano en sus medios periódicos.

Y finalmente, durante la censura política y religiosa instaurada por la Regeneración, Torres subvertirá su rol político y logrará estar en medio de las discusiones defendiendo las ideas por encima de los partidos, tal como lo establecerá en sus obras posteriores, como "La literatura y las ideas" y su famosa Ídola Fori $(1911)^{16}$, ambas ya prefiguradas en las páginas del suple-

${ }^{16}$ Véase: “La literatura y las ideas", en: Estudios Varios. La versión más actual en Obras: 2002a: 
mento, por ejemplo, en su corto estudio: "Paul Bourget" (N 432-21, del 11 de octubre de 1903: 321-328), escrito en 1891 pero publicado en 1903, en donde se sostiene la importancia de la propuesta filosófica de Torres: la necesidad de una literatura comprometida, una "literatura de ideas". En el texto Torres plantea que Bourget combina al artista y al filósofo, lo cual lo autoriza para expresar los males del siglo: "El escritor moderno para hacerse verdaderamente interesante debe reunir ambas condiciones: sentir mucho, pero pensar más todavía [...] Sólo á este precio podrá un pensador influir eficazmente en los destinos de su patria y de su siglo" (322-323) ${ }^{17}$; o en el ya citado "Del movimiento literario en la Europa contemporánea", en donde el autor expone la diversidad y la relatividad de las ideas en el mundo actual, tesis que desarrollará en detalle en Ídola Fori.

De esta manera, pensando en las ideas y no en los partidos logrará publicar en su suplemento autores tan cuestionados en la realidad política y religiosa colombiana de finales del siglo XIX y principios del XX, como lo fueron José María Vargas Vila, pero sobre todo, autores tales como Friedrich Wilhelm Nietzsche. Como era de esperarse, la empresa que significó El Nuevo Tiempo Literario cambiará de rumbo cuando el propio Torres acepte los cargos diplomáticos ofrecidos por los conservadores, y el diario y el suplemento, en lugar de ser censurados, serán adquiridos por Ismael Enrique Arciniegas, personaje consciente de sus diferencias con Torres, altamente conservador. De esta manera, El Nuevo Tiempo Literario no marcará en su segundo periodo un renacer literario, así como gran parte de los proyectos de la Regeneración no lograrán renovar una nación, ni tampoco se logrará ningún "renacimiento" como en el caso mexicano; y será tan sólo en tiempos de la República Liberal, en la década de 1930, luego de la caída del conservatismo, cuando se fortalecerán los diarios que incluso sobreviven en la actualidad junto con sus suplementos literarios, el caso de El Espectador y El Tiempo, dos ejemplos que justamente habían sido prefigurados por el primer gran periódico del siglo XX: El Nuevo Tiempo y su suplemento: El Nuevo Tiempo Literario.

347-361. Se trató del Discurso de Recepción en la Academia Colombiana, del 10 de julio de 1910. Ídola Fori, su más reciente edición en 2001: 1-198.

${ }^{17}$ Por ello Carlos Arturo Torres resalta el valor de la "novela analítica" de Bourget, la cual le permite la digresión intelectual. Asimismo, llama la atención sobre sus ensayos críticos y plantea que en el terreno intelectual llegará muy pronto una revolución en manos de Bourget e invita a todos sus contemporáneos colombianos a no permanecer en las orillas de la discusión. 


\section{REFERENCIAS}

Altamirano, Ignacio Manuel. 1988a. Escritos de literatura y arte. Tomo 1. En: Obras Completas. Tomo XIV. Selección y notas: José Luis Martínez, México: Secretaría de Educación Pública, 312 pp.

1988b. Escritos de literatura y arte. Tomo 2. En: Obras Completas.

Tomo XIV. Selección y notas: José Luis Martínez, México: Secretaría de Educación Pública, 356 pp.

. 1989. Escritos de literatura y arte. Tomo 3. En: Obras Completas. Tomo

XIV. Selección y notas: José Luis Martínez, México: Consejo Nacional para la Cultura y las Artes, 276 pp.

. 1958. Historia y política de México (1821-1882), México: Empresas Editoriales, 241pp.

Bedoya Sánchez, Gustavo Adolfo. 2010a. "Celebración de la independencia en la prensa literaria. El Papel Periódico Ilustrado y El Nuevo Tiempo Literario", en: Todos somos historia. Tomo 3: Control e Instituciones, Medellín: D’Vinni, 391-406 pp.

. 2010b. "La publicación de Dos libros de José Asunción Silva en El Nuevo Tiempo Literario. La emergencia y los límites del comentario crítico", en: Observaciones históricas de la literatura colombiana. Elementos para la discusión, Medellín: La Carreta Editores, 187-214 pp.

. 2011. "La prensa como objeto de investigación para un estudio histórico de la literatura colombiana. Balance historiográfico y establecimiento del corpus", en: Estudios de Literatura Colombiana, Medellín: Universidad de Antioquia, No 28, 89-109 pp.

El Nuevo Tiempo. 1902-1932. Bogotá: Editorial El Nuevo Tiempo. Redactores: Nicolás Pontón, José Camacho Carrizosa y Carlos Arturo Torres.

El Nuevo Tiempo Literario. 1903-1915, 1927-1929. Bogotá: Editorial La Crónica. Coordinación: Carlos Arturo Torres, Ismael Enrique Arciniegas y Eduardo Castillo.

El Renacimiento. 1869-1894. México, Imprenta de F. Díaz de Léon y Santiago White. Redactores: Ignacio Manuel Altamirano y Gonzalo A. Esteva. Chartier, Roger. 1994. El orden de los libros. Lectores, autores, bibliotecas en Europa entre los siglos XIV y XVII, Barcelona: Gedisa, 108 pp.

. 1999. Cultura escrita, literatura e historia, México: Fondo de Cultura Económica, $271 \mathrm{pp}$.

Horacio. 1776. El arte poética de Horacio, ó Epistola a los pisones, Traducida en verso Castellano por D. Tomas de Yriarte, Madrid: Imprenta Real de la Gazeta, LIII, 54 pp. 
McKenzie, Donald Francis. 1999. Bibliography and the Sociology of Texts: oral culture, literacy \& print in early New Zealand, Cambridge: Cambridge University Press, $143 \mathrm{pp}$.

Sánchez Castro, Alejandro. 1964. Altamirano como militar, México: s.e., 31 pp.

Torres, Carlos Arturo. 2001. Obras. Tomo I. Idola Fori y Escritos políticos. Presentación, prólogo y notas por Rubén Sierra Mejía, Bogotá: Instituto Caro y Cuervo, LXII, $821 \mathrm{pp}$. . 2002a. Obras. Tomo II. Ensayos históricos y literarios. Prólogo, compilación y notas por Rubén Sierra Mejía, Bogotá: Instituto Caro y Cuervo, $\mathrm{XV}, 513 \mathrm{pp}$.

. 2002b. Obras. Tomo III. Estudios literarios. Prólogo, compilación y notas por Rubén Sierra Mejía, Bogotá: Instituto Caro y Cuervo, 575 pp.

Vallejo Mejía, Mariluz. 2006. A plomo herido. Una crónica del periodismo en Colombia (1880-1980), Bogotá: Planeta, 430 pp.

Williams, Raymond. 1980. Marxismo y literatura, Barcelona: Ediciones Península, $250 \mathrm{pp}$. 